\title{
Everyday pain in three- to five-year-old children in day care
}

\author{
Carl L von Baeyer $\mathrm{PhD}^{1}$, Shannon Baskerville MA ${ }^{1}$, Patrick J McGrath $\mathrm{PhD}^{2}$
}

\section{CL von Baeyer, S Baskerville, PJ McGrath. Everyday pain in three- to five-year-old children in day care. Pain Res Manage 1998;3(2):111-116.}

A new event sampling instrument, the Dalhousie Everyday Pain Scale, was used to observe 50 children in six day care centres in Saskatoon for an average of $2.24 \mathrm{~h}$ each. The nature of minor painful incidents (eg, collisions and falls) was recorded, including distress behaviours and responses from peers and adults. Twenty-nine children $(58 \%)$ were observed to experience one or more painful incidents, producing a total of 51 incidents and yielding a median rate of incidents of 0.31 per child per hour, a rate similar to that reported in another Canadian sample. Seven of nine child response items met criteria for reliability in a subsample of incidents observed simultaneously by two observers. Rubbing the affected body part, crying and making verbal statements about the injury were the most common responses to painful incidents. Intervention by day care staff was strongly associated with children's facial expression of distress: physical and first aid interventions were offered most frequently to children who displayed the greatest facial distress. Content analysis of observers' records produced a classification scheme for causes of painful incidents. Twenty per cent of painful incidents were judged to be the result of deliberate actions by other children. The classification of causes may be a useful addition to the scale for application in future studies of everyday pain and injury prevention.

Key Words: Child, Day care, Event sampling, Everyday pain, Pain behaviour

\section{La douleur au quotidien chez les enfants des garderies âgés de trois à cinq ans}

RÉSUMÉ : On a observé 50 enfants de six garderies de Saskatoon pendant une moyenne de 2,24 heures chacun au moyen d'un nouvel outil d'échantillonnage des incidents douloureux, le Dalhousie Everyday Pain Scale. La nature des incidents douloureux mineurs (p. ex., collisions, chutes) a été consignée, y compris les comportements de détresse et les réactions des semblables et des adultes. On a signalé un incident douloureux ou plus chez vingt-neuf enfants (58\%) totalisant 51 incidents et générant un taux médian d'incidents de 0,31 par enfants par heure, taux semblable à celui d'un autre échantillon étudié au Canada. Sept des éléments de mesure de la réaction des enfants sur neuf répondaient à des critères de fiabilité dans un sous-échantillon d'incidents observés simultanément par deux observateurs. Une friction à l'endroit endolori, les pleurs et la verbalisation ont été les réactions les plus courantes aux incidents douloureux. L'intervention du personnel de la garderie a été fortement associée au faciès de l'enfant en détresse : en général, ce sont les enfants qui s'exprimaient par le visage qui ont le plus fait l'objet de manifestations physiques d'attention et qui ont reçu des premiers soins. L'analyse du contenu des dossiers des observateurs a donné lieu à une classification des causes des incidents douloureux. On a estimé que vingt pour cent des incidents douloureux ont été le résultat de gestes délibérés de la part d'autres enfants. La classification des causes pourrait se révéler un ajout utile à l'échelle d'évaluation lors de prochaines études sur la douleur et la prévention des accidents.
$\mathrm{M}$ inor everyday bumps and scrapes, which rarely result in any observable physical injury or lasting pain, are more frequent causes of pain in children than are medical procedures or illnesses (1-4). However, little research has ex- plored this aspect of children's pain experience. Fearon et al (5) argue that these minor painful incidents, or 'booboos', may have considerable influence on children's development of pain coping strategies because they occur frequently and

\footnotetext{
${ }^{1}$ Department of Psychology, University of Saskatchewan, Saskatoon, Saskatchewan; ${ }^{2}$ Department of Psychology, Dalhousie University, Halifax, Nova Scotia

Correspondence and reprints: Dr CL von Baeyer, Department of Psychology, University of Saskatchewan, Saskatoon, Saskatchewan S7N 5A5. Telephone 306-966-6676, fax 306-966-6630, e-mail carl.vonbaeyer@usask.ca

Received for publication July 31, 1997. Accepted March 19, 1998
} 
take place in a normal social environment where different styles of expressing and coping with pain may be reinforced. Consequently, the study of children's everyday pain may provide important information regarding children's experience with and understanding of pain.

As noted by Fearon et al (5), the study of children's everyday pain is fraught with many methodological difficulties, none of which can be addressed by the numerous pain scales designed for clinical applications. Those authors argue that, given the dynamic nature of the social and behavioural contexts in which everyday pain occurs, an investigation must include naturalistic observation, which, if done individually, can be costly and time-consuming. To address the issue of inadequate methodology for studying everyday pain in children, Fearon et al (5) developed the first instrument for the systematic observation of such incidents in groups of children: the Dalhousie Everyday Pain Scale (5). This instrument, which achieved excellent interrater reliability in the first published report, uses event sampling; recording is carried out whenever a defined target behaviour occurs, in this case a painful incident. The scale includes checklists and rating scales designed to describe the location, behavioural context and nature of a painful incident, together with the response to the incident by the subject, other children and caregivers. These researchers recorded that there was one incident of everyday pain every $3 \mathrm{~h}$ per child during free play in day care centres in 53 children aged 28 to 81 months. No age or sex differences were reported in the severity or frequency of painful incidents. However, girls responded to incidents with more distress responses (involving sobbing, crying, screaming or anger) and for longer periods than did boys, and girls' pain elicited more responses than boys' pain from adults caregivers.

The purpose of the current study was to replicate and extend the findings of the study by Fearon et al (5). Demonstrating similar rates of everyday pain incidents in a different setting and corroborating the interrater reliability of measures obtained by relatively untrained observers would strengthen the generalizability of the Dalhousie Everyday Pain Scale for research and applied use. We also extended their work by examining the circumstances surrounding each incident reported and developing a system for categorizing incidents into several common types, making the Dalhousie Everyday Pain Scale a more comprehensive instrument.

\section{Setting and subjects}

\section{METHODS}

Fifty children, 28 boys and 22 girls, were recruited as participants from six urban day care centres in Saskatoon, Saskatchewan after institutional ethics approval was obtained. Several care centres were used so that any anomalous results could not be attributed simply to having chosen a particularly safe or dangerous centre. Day care staff gave parents of three- to five-year-olds a written form requesting consent to observe their children. Parents were informed that we would not be interacting with their children, only observing them during their normal activities at day care. The con- venience sample employed in this study comprised all children for whom parental consents were obtained. The mean age of the participants was 52.6 months, range 36.8 to 67.8 months.

\section{Selection and training of observers}

Twenty observers ( 15 of whom were women) contributed to data collection. Fourteen observers were undergraduate students enrolled in a senior laboratory course in developmental psychology, four were graduate students participating in a pediatric pain research team, one was a paid undergraduate research assistant and one was the first author (who contributed about $2 \%$ of the total observation hours). Only 40 mins of training was offered, which began with the observers familiarizing themselves with the behavioural definitions accompanying the Dalhousie Everyday Pain Scale (5). Observers then practised use of the scale while watching four videotaped booboos: three falls and collisions simulated by four-year-old boys and one, a dog nipping a four-year-old girl, that had occurred naturally. After each incident was rated on all scales, the ratings were discussed and discrepancies resolved. Reliability was not measured using the training videotapes.

\section{Measure}

The Dalhousie Everyday Pain Scale (1994 revision) consists of four sections. The first portion comprises a description of the incident, including a rating of the observer's perception of the severity of the incident, and identification of the body parts involved.

The next section describes the subject's response using different indexes. In this section, the Faces Pain Scale (6) was used to estimate the facial expression of distress. Although this scale was initially designed and validated for children's use in self-rating their pain, several studies support the use of the Faces Pain Scale by adults to measure children's pain $(7,8)$. A checklist was also used to capture the presence of pain behaviours such as rubbing, crying and withdrawal. Finally, an estimate of the duration of the pain behaviour in seconds was recorded.

In the third section, the adult response was identified (none, distraction, verbal, physical and/or first aid).

In the last section, the behavioural context of the incident was described in terms of activity level and emotional tone of the play occurring at the time of the incident, number of participants, behavioural restrictiveness of the situation, proximity of adults and location (indoor or outdoor).

After training and practice, observers take about $1 \mathrm{~min}$ to complete the Dalhousie Everyday Pain Scale following observation of each incident. An incident was defined, as per Fearon et al (5), as any event of bodily contact with a person or object that met either or both of the following criteria: first, the observer judged that if she or he had experienced the event in the child's place, the observer would have felt at least momentary, minor discomfort; second, the event resulted in distress, anger or protective reaction on the part of the child. 


\begin{tabular}{|c|c|}
\hline \multicolumn{2}{|c|}{$\begin{array}{l}\text { TABLE } 1 \\
\text { Number of children by number of incidents observed }\end{array}$} \\
\hline Number of painful incidents & Number $(\%)$ of children \\
\hline 0 & $21(42)$ \\
\hline 1 & $15(30)$ \\
\hline 2 & $8(16)$ \\
\hline 3 & $4(8)$ \\
\hline 4 & $2(4)$ \\
\hline 5 or more & 0 \\
\hline
\end{tabular}

\section{Procedure}

Children were observed in their normal day care environment; no changes were made in the program to accommodate this study. We observed all children for whom consent had been completed and who were present in the class, up to a maximum of five subjects at a time per observer. (We had previously determined in pilot work that it was too difficult to keep track of more than five children at a time.) Where it was necessary to avoid observing some children to keep the total number below five, the selection was made at random or on the basis of proximity to the observers at the time of observation.

Observations were carried out for 1 to $2 \mathrm{~h}$ periods in a nonuniform rate over the course of the day to accommodate the class schedules of the undergraduate student observers. The observations were carried out during the periods from 10:00 to $11: 30$ and from 15:00 to 17:00, when children tended to be involved in active play. Observations were not carried out during meals and rest times. In addition, the observations were carried out in August through October, a time when children in day care spend a lot of time in the outdoor playground. Thus, the observations were not representative of the full range of time children spend in day care; we observed at times when painful incidents were relatively more probable, and $88 \%$ of the observed incidents occurred outdoors.

Interrater reliability data were collected at various sessions throughout the study. The goal to have teams of two individuals carry out as much of the observation as possible was met for $76 \%$ of the observation hours. Eighteen of the 50 children were observed simultaneously by two observers for a total of $47.1 \mathrm{~h} ; 28$ children were observed by two observers for $55.9 \mathrm{~h}$ as well as by one observer for $27.1 \mathrm{~h}$; and four children were observed by only one observer for a total of $5.5 \mathrm{~h}$. The total amount of observation time was 135.7 child hours. The mean amount of observation time was $2.24 \mathrm{~h} /$ child during observation by two observers; it was $1.02 \mathrm{~h} /$ child during observation by one observer.

When two observers were collecting data simultaneously, they were instructed to stand about 2 to $4 \mathrm{~m}$ apart and to position themselves to allow a similar visual range of the observation area but to discourage unintentional cueing of one another. The observers coordinated the beginning of their ob-

\section{TABLE 2}

Interrater reliability coefficients for categorical observational variables reflecting subjects' response to pain and percentage of incidents in which each behaviour occurred

\begin{tabular}{lcc}
\hline $\begin{array}{l}\text { Subject response } \\
\text { variable (coded as } \\
\text { present/absent) }\end{array}$ & $\begin{array}{c}\text { Kendall's } \tau \text { in } \\
\text { reliability sample of } \\
\text { 21 incidents }\end{array}$ & $\begin{array}{c}\text { Frequency in full } \\
\text { sample of 51 } \\
\text { incidents }\end{array}$ \\
\hline Rubbing & 0.71 & $51 \%$ \\
Verbal pain statement & 0.63 & $57 \%$ \\
Crying & 1.00 & $29 \%$ \\
Screaming & 1.00 & $16 \%$ \\
Anger & 0.01 & $14 \%$ \\
Help-seeking/ & 0.91 & $31 \%$ \\
$\quad$ emotional support & 1.00 & $4 \%$ \\
Clinging & 0.84 & $6 \%$ \\
Withdrawal & 0.84 & $14 \%$ \\
Reduced activity & & \\
\hline
\end{tabular}

servation period and wrote down the exact time and first names of children involved in each incident to ascertain whether the two raters were referring to the same incident.

\section{Content analysis of causes of injury}

Observers were asked to write a brief description of each incident on their checklists. These descriptions were later transcribed onto index cards which were then sorted into categories by a researcher (the second author) who was trained and experienced in qualitative research methods. The categories were not set a priori but emerged from iteratively examining the data. Each category was maintained only if it contained at least five incidents (about 10\% of the total number of incidents observed); categories initially containing fewer than five incidents were merged with other categories. Interrater agreement was not measured empirically but was addressed by discussion of incidents in which the coding was ambiguous and of incidents in which different coding was applied to the same incident based on different observers' written descriptions.

\section{Rate of incidents}

\section{RESULTS}

We observed 51 incidents over the course of 135.7 child hours of observation. The modal number of incidents per child was zero; 21 children (42\%) did not get hurt during the observation periods. The number of children experiencing incidents is shown in Table 1. The median and mean rates were 0.310 and 0.413 incidents per child per hour, respectively.

\section{Interrater reliability}

During the 103 child hours in which two observers were observing simultaneously, 21 incidents experienced by 16 different children were recorded by both observers. Because all but two of the items were nominal or ordinal scales, Ken- 


\begin{tabular}{|c|c|}
\hline \multicolumn{2}{|c|}{$\begin{array}{l}\text { TABLE } 3 \\
\text { Interrater reliability coefficients for categorical } \\
\text { observational variables reflecting behavioural context, } \\
\text { setting and adult response }\end{array}$} \\
\hline Incident & $\begin{array}{c}\text { Kendall's } \tau \text { in reliability sample } \\
\text { of } 21 \text { incidents }\end{array}$ \\
\hline Severity of incident & 0.81 \\
\hline $\begin{array}{l}\text { Adult response (none to } \\
\text { first aid) }\end{array}$ & 0.87 \\
\hline Activity level (seated to active) & 0.50 \\
\hline Tone (calm to agitated) & 0.17 \\
\hline Number of participants & 0.32 \\
\hline $\begin{array}{l}\text { Personal control } \\
\quad \text { (restrictiveness) }\end{array}$ & 0.17 \\
\hline Adult proximity (near to far) & 0.30 \\
\hline Location (indoor-outdoor) & 0.69 \\
\hline
\end{tabular}

TABLE 4

Adult response to pain: Frequency of response categories and relationship to child's facial expression

\begin{tabular}{lcc}
\hline $\begin{array}{l}\text { Adult response to } \\
\text { incident }\end{array}$ & $\begin{array}{c}\text { Number (\%) } \\
\text { of incidents }\end{array}$ & $\begin{array}{c}\text { Mean child facial } \\
\text { expression rating* }\end{array}$ \\
\hline None & $21(43)$ & 2.52 \\
Distraction & $1(2)$ & 3.00 \\
Verbal & $10(20)$ & 3.50 \\
Physical & $15(29)$ & 5.00 \\
First aid & $3(6)$ & 6.67 \\
\hline
\end{tabular}

${ }^{*} F=8.97, P<0.001$

dall's , a nonparametric measure of association between categorical variables, was used to estimate interrater reliability. Pearson correlations were used to estimate the interrater reliability of the number and duration of pain behaviours, and of the Faces Pain Scale for facial expression of pain (which approximates an interval scale). The reliability for the number of different pain responses was 0.91 , and for the duration of the pain response it was 0.50 . The reliability for the seven-point Faces Pain Scale was 0.92. The reliability estimates for subject response variables are shown in Table 2 and for setting and context variables are outlined in Table 3.

\section{Effects of sex and age}

The mean rate of incidents for boys was 0.422 incidents per child per hour of observation, while the mean rate for girls was 0.401; this difference was not significant $\left({ }^{2}=0.55, \mathrm{P}>0.4\right)$.

Using Kruskal-Wallis one-way ANOVA by ranks, all other observational variables were tested for sex differences. The only statistically significant difference was in expression of anger. A display of anger was reported for seven of the 32 incidents involving boys $(22 \%)$ but in none of the 19 incidents involving girls ( $\left.{ }^{2}=4.72, \mathrm{P}<0.03\right)$. No significant inter-

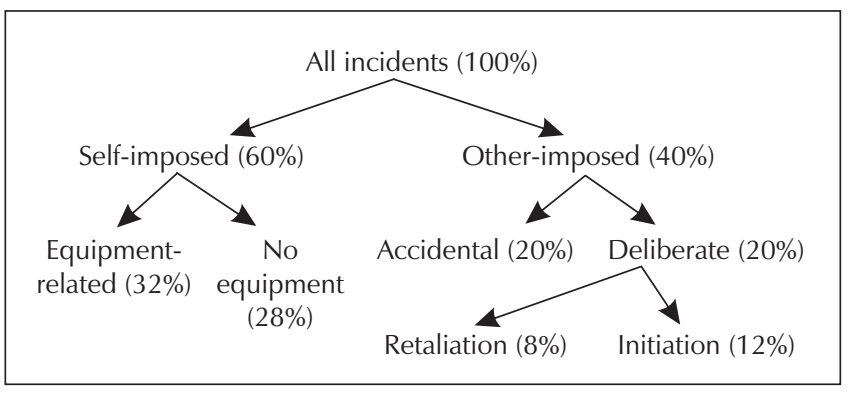

Figure 1) Content analysis: Percentage of incidents accounted for by various causes

action of subject sex by observer sex was found; female observers were as likely as male observers to report anger in boys. However, the interrater agreement for anger was close to zero, making the latter findings equivocal.

No significant relationship was found between sex and the classification of the cause of the incident (self-imposed versus other-imposed); $42 \%$ of incidents involving girls and $39 \%$ of those involving boys were assessed as other-imposed incidents, suggesting that experiences of pain as a result of aggression by other children were not more frequent in one sex.

Fearon et al (5) reported that girls expressed more severe distress than boys. In the present sample, the mean facial expression score for boys was 3.38 and for girls was 4.33, a nonsignificant finding in the same direction as previously reported (Student's $t$ test $=1.71, \mathrm{P}<0.09$ ). Similarly, two of the 19 incidents involving girls, but none of the 32 incidents involving boys, included an observation of clinging to an adult as part of the distress response $\left({ }^{2}=3.50, \mathrm{P}<0.06\right)$. Age was not significantly associated with any of the observational variables.

\section{Individual differences}

Rates of painful incidents per child per hour of observation ranged widely, from 0 (the modal rate) to 3.0. There was a tendency for children who had a higher rate of injury to have been hurt by objects (balls, shovels, etc) as opposed to the other coded causes, such as another child or adult; five of 20 incidents involved objects in children hurt three or four times, versus none of 31 incidents in children hurt two or fewer times ( $\left.{ }^{2}=7.94, \mathrm{P}<0.05\right)$. However, there was no association between the cause of injury and the intensity of expressed pain or the frequency of pain behaviours.

\section{Adult response}

Adult response was strongly associated with the severity of distress displayed by the child, as shown by the child facial expression scores in Table 4. Children who received first aid had a mean facial distress score close to the top of the scale, while those who received no adult response showed little facial expression of distress.

\section{Content analysis of causes of injury}

Fifty incidents were coded with the cause of the injury, based on observers' written descriptions. For one incident the description was too brief to permit coding. The categorical 
framework that arose from the content analysis, together with the percentage of incidents comprising each category, is depicted in Figure 1.

The incidents in the Self-imposed - Equipment-related category included falling from or colliding with playground equipment such as slides, swings or tricycles. Most of the incidents in the Self-imposed - No equipment category occurred when children tripped and fell while running. The Other-imposed - Accidental category included incidents of inadvertent pushing, tripping or collisions with another child. The Other-imposed - Deliberate category included incidents of hitting, pinching, biting, kicking and throwing sand in the eyes. In this category, approximately equal numbers of incidents reflected subcategories labelled Initiation (meaning that no prior aggressive action had been observed) and Retaliation (meaning that the aggressive action appeared to be in reciprocation for a preceding incident of aggression).

\section{DISCUSSION}

The Dalhousie Everyday Pain Scale is the first standardized measure of everyday pain in young children. The present study provides some external confirmation of the scale's reliability and practical utility. Our study was in most ways a replication of the initial work by Fearon and coworkers (5), but there are some appreciable differences. In the study by Fearon et al, data were collected by a trained observer whose reliability was probably increased by her personal involvement in the study and her accumulation of hundreds of hours of observation experience. We wished to find out whether the reported excellent reliability of the Dalhousie Everyday Pain Scale would be maintained when the scale was applied by less experienced and less involved observers, as would probably be the case in many future applications of the scale employing day care workers, parents or students as observers.

In the present study, 20 observers participated in data collection, each with only 40 mins of training using videotape and with no subsequent follow-up to maintain reliability. In this context, it is impressive that the reliability coefficients for nearly all of the child response variables were maintained at adequate to high levels. In particular, the rating of pain as reflected in the child's facial expression yielded an interrater reliability correlation coefficient of 0.92 , indicating excellent agreement on a very important component of the Dalhousie Everyday Pain Scale. However, most of the measures of contextual variables, and of anger, did not produce satisfactory reliability estimates, in most cases probably because of restricted range on the scales. Another possible explanation for the low reliability (and low base rate) for anger could be reluctance on the part of less experienced adult observers to assign a negative emotion such as anger to young children's experiences. Also, observers may have made inappropriate assumptions regarding the legitimacy of children's anger responses by applying the same criterion to incidents of anger (would this have made me angry?) as they did to pain (would this have hurt me?).

In the present study, the median rate of painful incidents was 0.31 per child per hour and the mean rate was 0.41 . (The mean was larger than the median because of the inclusion of a few children who were hurt repeatedly in a short time; on the other hand, $42 \%$ of the children did not experience painful incidents while being observed.) The overall rates are quite comparable with the mean rate of 0.34 incidents per child per hour reported by Fearon et al (5). In both studies, no observations were carried out during nap time (we also excluded meal times); our observation periods tended to be vigorous play times. Fearon et al showed that the rate of injuries is strongly affected by the time of day and the nature of the activities in which the children are engaged; the peak rates that occurred in their study were around 10:00 and 15:00, which were the primary times of observation in our study. Thus, the rate of injury is probably inflated to some extent in both studies, somewhat more so in the present study than in that reported by Fearon et al.

In the original study by Fearon et al (5), girls expressed distress more intensely than boys and received physical comfort more often than boys. Our findings for facial expression and clinging were in the same direction but were not significant. The only significant sex difference in our study was in anger, where our finding was opposite that of Fearon et al. In our study, only boys were observed to express anger, whereas Fearon et al reported that girls expressed anger more frequently. We speculated that the low interrater agreement and higher rate of anger in boys could be related to the sex of the observers, but no such interaction was found, nor could the sex difference in anger be attributed to differences in the number of incidents attributed to aggressive acts by others, which occurred at about the same rate in both sexes.

It should, however, be noted that in our study the anger measure was not reliable. In some ways this exploration of sex differences mirrors findings in the larger field of research on sex differences in children's pain expression, where findings are often inconsistent and differences, when found, are not large (9).

Children in our study ranged from 36 to 67 months old. We found no significant relationships between age and any other variable. This finding, probably indicating the effects of a restricted range of ages, was consistent with the results of Fearon et al (5) who reported only a very weak $(\mathrm{r}=0.10)$ correlation between age and help-seeking, with younger children seeking help more frequently. When pain in a wider age range of children is studied, older children often show lower levels of self-rated distress and of overt distress behaviours. It is worth noting that Fearon et al observed only one incident in the age range of 84 to 95 months and so did not include these older children in their analyses.

The adult response to painful incidents ranged from no response (in $43 \%$ of incidents) to first aid (in 6\%). Not surprisingly, the adult response was strongly associated with the intensity of the child's distress, with first aid and physical interventions (eg, picking the child up) occurring more often when the child showed a high degree of distress. A much more microscopic temporal analysis is required to determine to what extent strong facial expressions of distress elicited 
stronger adult responses, as opposed to the availability of adult hugging, etc, eliciting or reinforcing greater expressions of distress in the children. Both probably occur at times (as all parents know).

A content analysis on the observers' reports of incidents, created by using a lengthy iterative process, produced a classification of the perceived antecedents or causes. This classification could, if cross-validated, lead to a useful addition to the Dalhousie Everyday Pain Scale. About $60 \%$ of incidents in our sample were described as self-imposed, ie, not induced by another child's action, while $40 \%$ were attributed to actions by other children, of which over half seemed to be deliberate. Half of these deliberate actions, in turn, were judged to be retaliatory and the other half were judged to be initiations of aggression.

The Dalhousie Everyday Pain Scale focuses on the recipient, rather than the perpetrator, of careless and aggressive actions. If these judgements are reliable, they could be quite useful, for example in the following studies: first, in studies of interventions to alter aggressiveness in groups of preschool children where aggression is of concern (also to study whether adult response varies depending on whether the child is perceived as a victim or a perpetrator); second, in studies of sequences of bully-victim reciprocal behaviour in early childhood; and, finally, in studies of injury prevention based on design of playground equipment.

Based on anecdotal information from several observers, it appears that many of the incidents involving younger children were brought about by their unskilled use of playground

\section{REFERENCES}

1. Savedra M, Gibbons P, Tesler J, Wegner C. How do children describe pain? Pain 1982;14:95-104.

2. Ross DM, Ross SA. Childhood pain: The school-aged child's viewpoint. Pain 1984;20:179-91.

3. Gaffney A, Dunne EA. Children's understanding of the causality of pain. Pain 1987;29:91-104.

4. Harbeck C, Peterson L. Elephants dancing in my head: A developmental approach to children's concepts of specific pains. Child Dev 1992;63:138-49.

5. Fearon I, McGrath PJ, Achat H. "Booboos": The study of everyday pain among young children. Pain 1996;68:55-62.

6. Bieri D, Reeve RA, Champion GD, Addicoat L, Ziegler JB. The Faces equipment designed for older, more physically skilled children. However, we found no age differences in rates of painful incidents within the restricted age of our sample.

Everyday pain constitutes minor bumps and collisions that produce distress of a mild intensity and short duration, and which usually do not require intervention beyond reassurance. The importance of these incidents lies in that they offer daily training for young children in the domain of social response to pain, anxiety and anger: help-seeking versus selfsoothing, and retaliation versus conciliation. While this process, for most children, proceeds unremarkably, a minority of children receive repeated practice and reinforcement in behavioural sequences that eventually become maladaptive, with serious social consequences; for example, being excessively dependent on adults to soothe minor discomforts, angrily striking out against other children when accidentally bumped, or dissimulating or exaggerating pain in order to get attention. Accurately measuring the response to minor painful incidents by children and by other children and adults will contribute to research on these issues in social development.

ACKNOWLEDGEMENTS: Appreciation is expressed to Eldon Siemens for assistance in organizing the data collection and to Belinda Goodenough for her comments on the manuscript. We also gratefully acknowledge the participation and support of 18 graduate and undergraduate students, and of staff, parents and children at six participating day care centres in Saskatoon, Saskatchewan.

Pain Scale for the self-assessment of the severity of pain experienced by children: development, initial validation and preliminary investigation for ratio scale properties. Pain 1990;41:139-50.

7. Goodenough B, Addicoat L, Champion GD, et al. Pain in 4- to 6-year old children receiving intramuscular injections: A comparison of the Faces Pain Scale with other self-report and behavioural measures. Clin J Pain 1997;13:60-73.

8. Goodenough B, Kampel L, Champion GD, et al. An investigation of the placebo effect and age-related factors in the report of needle pain from venipuncture in children. Pain 1997;72:383-91.

9. Unruh A. Gender variations in clinical pain experience. Pain 1996;65:123-67. 


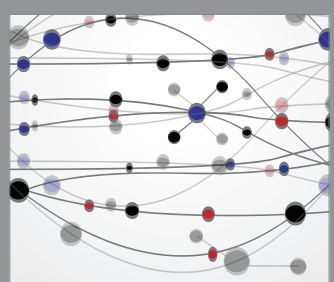

The Scientific World Journal
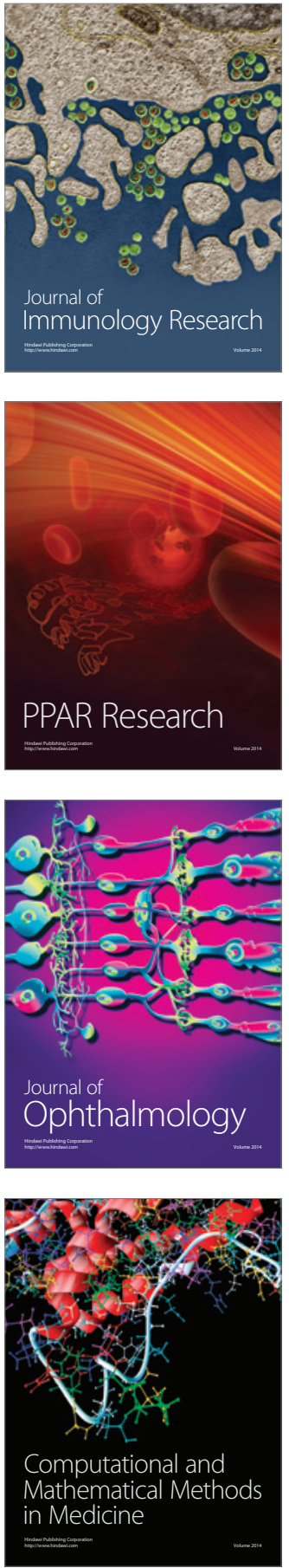

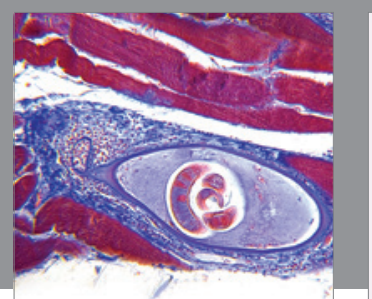

Gastroenterology Research and Practice

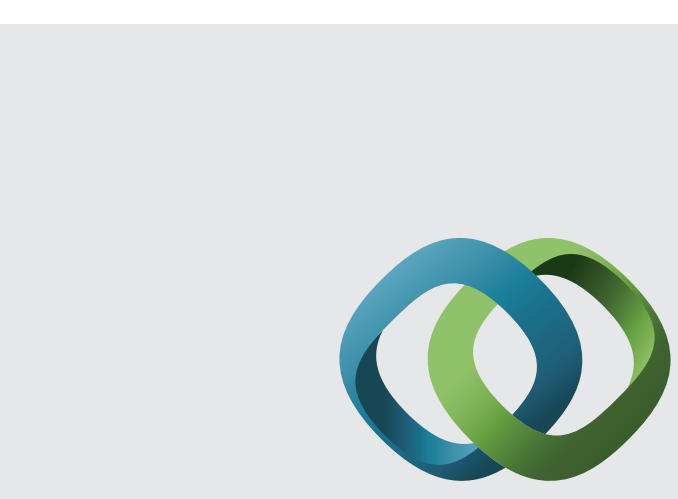

\section{Hindawi}

Submit your manuscripts at

http://www.hindawi.com
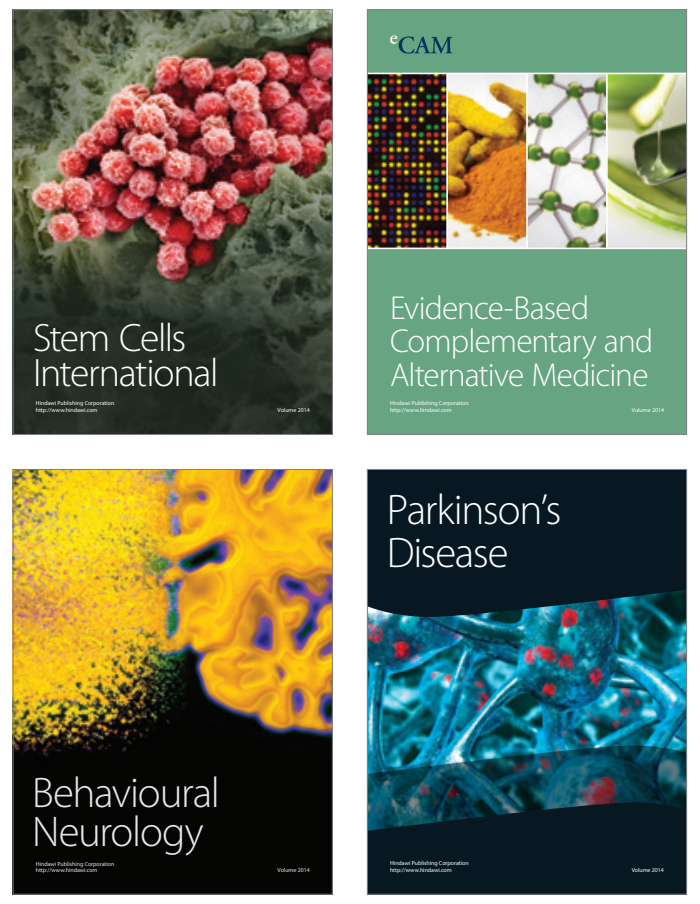
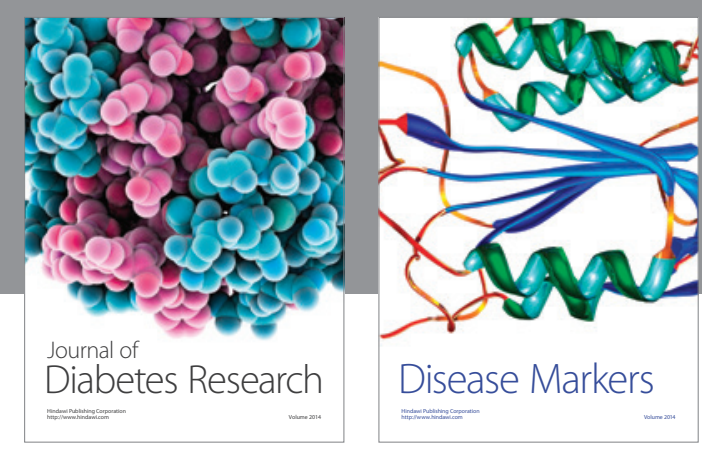

Disease Markers
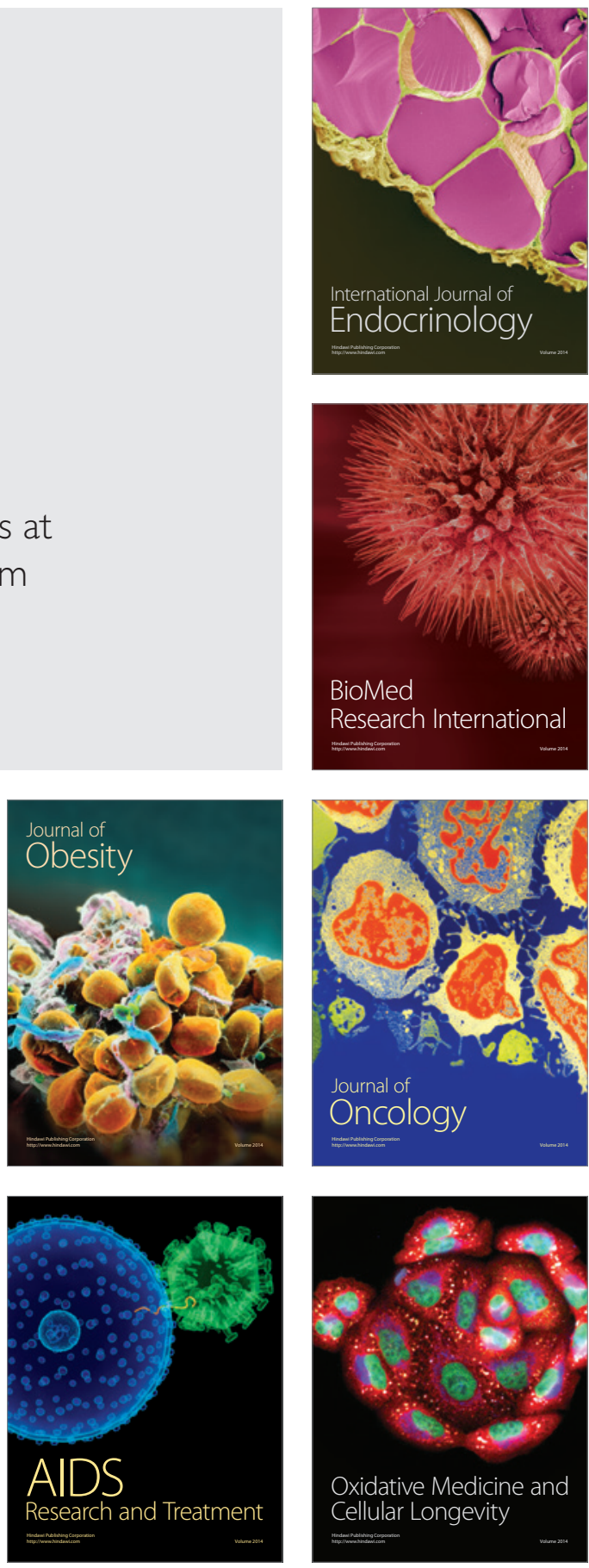